DOSSIÊ "Georges Canguilhem, a história e os historiadores"

\title{
Senderos Encontrados: Canguilhem y la escuela de los Annales ${ }^{1}$
}

\author{
Francisco Vázquez Garcia \\ Profesor de la Facultad de Filosofia y Letras, Universidad de Cádiz \\ Cádiz - España \\ francisco.vazquez@uca.es
}

Recebido em 05/02/2016. Aprovado em 20/04/2016.

Como citar este artigo: Garcia, Francisco Vázquez. "Senderos Encontrados: Canguilhem y la escuela de los Annales". Intelligere, Revista de História Intelectual, São Paulo, v. 2, n. 1 [2], p. 36-50. 2016. ISSN 2447-9020. Disponível em

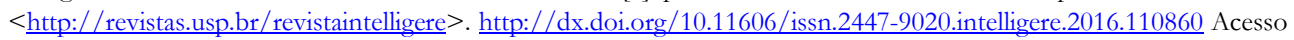
$\mathrm{em} \mathrm{dd} / \mathrm{mm} /$ aaaa.

Resumen: En este artículo se analiza la recepción de la escuela de los Annales en la obra de Georges Canguilhem. Habitualmente se suele destacar el paralelismo y, al mismo tiempo, el desconocimiento recíproco entre los historiadores del grupo de los Annales y los representantes de la epistemología histórica francesa (Cavaillès, Koyré, Bachelard, Canguilhem). Este último, sin embargo, constituye una excepción, pues conocía muy bien la obra de lo que denominaba "equipo de Estrasburgo" (Febvre, Bloch, Halbwachs). Utilizando abundantes fuentes inéditas, se trata de mostrar que este encuentro marcó decisivamente el estilo de epistemología histórica practicado por Canguilhem.

Palabras clave: Canguilhem, escuela de los Annales, historiografía, epistemología histórica.

\section{Caminhos descobertos: Canguilhem e a escola dos Annales}

Resumo: Neste artigo analisamos a recepção da escola dos Annales na obra de Georges Canguilhem. Habitualmente, tende-se a destacar o paralelismo e, ao mesmo tempo, o desconhecimento recíproco entre os historiadores do grupo dos Annales e os representantes da epistemologia histórica francesa (Cavaillès, Koyré, Bachelard, Canguilhem). Este último, no entanto, constitui uma exceção, pois conhecia muito bem a obra do que denominava "equipe de Estrasburgo" (Febvre, Bloch, Halbwachs). Utilizando abundantes fontes inéditas, tentamos mostrar que esse encontro marcou decisivamente o estilo de epistemologia histórica praticado por Canguilhem.

Palavras-chave: Canguilhem, escola dos Annales, historiografía, epistemologia histórica.

\footnotetext{
${ }^{1}$ Este trabajo se ha realizado en el marco del grupo de investigación "El problema de la alteridad en el mundo actual" (HUM-536), de la Universidad de Cádiz.
} 


\title{
Paths discovered: Canguilhem and the Annales scholl
}

\begin{abstract}
In this paper we analyze the reception of the Annales school in the work of Georges Canguilhem. Usually scholars tend to emphasize the parallel and at the same time, the mutual ignorance among historians of the Annales group and representatives of the French historical epistemology (Cavaillès, Koyré, Bachelard, Canguilhem). The latter, however, is an exception, because he was very familiar with the work of what he called "team of Strasbourg" (Febvre, Bloch, Halbwachs). Using abundant unpublished sources, we try to prove that this meeting decisively affected the historical epistemology practiced by Canguilhem.
\end{abstract}

Keywords: Canguilhem, Annales school, historiography, historical epistemology.

\section{Introducción. Un encuentro fracasado: escuela de los Annales y epistemología histórica francesa}

A finales de la década de 1960, Michel Foucault aludió al "entrecruzamiento"2 de la historia social al estilo de los Annales, ${ }^{3}$ con la epistemología histórica francesa. Calificó este acontecimiento como una "mutación epistemológica de la historia"4 y situó su propio proyecto arqueológico como una prolongación de este suceso en el ámbito de la historia intelectual. Desde entonces los comentaristas no han dejado de resaltar el estrecho paralelismo y las convergencias entre ambas orientaciones.

Se han subrayado, por ejemplo, las concordancias existentes entre las concepciones de la ciencia exhibidas por Marc Bloch y Georges Canguilhem; ${ }^{5}$ el parentesco entre el discontinuismo histórico y la crítica del "precursor" en este último y motivos similares en la obra de Lucien Febvre. ${ }^{6}$ Se han enfatizado las coincidencias epistemológicas entre Bachelard y

${ }^{2}$ M. Foucault, L'archéologie du savoir (Paris: Gallimard, 1969), 13.

3Ibid., 21. Aunque en L'archéologie du savoir Foucault no utiliza la denominación de "Annales" ni menciona nombres propios de historiadores asociados a este grupo, en otros textos anteriores sí lleva a cabo esta identificación: Michel Foucault, "Sur les façons d'écrire l'histoire" (1967), en Dits et Écrits, tome I (Paris: Gallimard, 1994), 585-600, 585; Michel Foucault, "Qui êtes-vous, professeur Foucault?" (1967), en Dits et Écrits, tome I, 601-620, 606-607; Muchel Foucault, "Foucault répond à Sartre" (1968), en Dits et Écrits, tome I, 662-668, 667, y posteriores: Michel Foucault, "Michel Foucault explique son dernier livre" (1969), en Dits et Écrits, tome I, 771-779, 773; Michel Foucault, "La naissance d'un monde" (1969), en Dits et Écrits, tome I, 786-789, 787; Michel Foucault, "Revenir á l'histoire" (1972), en Dits et Écrits, tome II (Paris: Gallimard, 1994), 268-281, 276-77; Michel Foucault, "L'oeil du pouvoir" (1977), en Dits et Écrits, tome III (Paris: Gallimard, 1994), 190-207, 193 y Michel Foucault, "La scène de la philosophie" (1978), en Dits et Écrits, tome III, 571-595, 580. Louis Althusser y Étienne Balibar, Para leer el capital (México: Siglo XXI, 1974), 50-52, en la misma época que Foucault advertían en los epistemólogos de tradición francesa (Cavaillès, Bachelard, Koyré, Canguilhem y el propio Foucault) una revolución historiográfica que venía a cuestionar la concepción hegeliana e historicista de la historia. En el caso de los historiadores de Annales (Fenbre, Labrousse, Braudel), el cambio sería mucho más limitado y menos decisivo. Describen la multiplicidad de tiempos históricos (frente a la noción homogénea y lineal del tiempo propia del historicismo), pero son incapaces de formular su concepto rompiendo realmente con la imagen común del tiempo como una sucesión continua, Ibid., 106-107.

${ }^{4}$ M. Foucault, L'archéologie, 21. Esta "mutación" se remontaría a Marx, pero habría tardado bastante tiempo en dejar sentir sus efectos.

${ }^{5}$ P. Ricoeur, Histoire et vérité (Paris: Seuil, 1972), 26-27.

${ }^{6}$ D. Mann, Lucien Febure. La pensée vivante d'un historien (Paris: Armand Colin, 1973), 138-139; F. Dosse, La bistoria en migajas. De los "Annales" a la "nueva historia" (Valencia: Edicions Alfonso El Magnánim, 1988), 53-54. 
este historiador, ${ }^{7}$ y entre el rechazo del anacronismo y de la búsqueda de precursores en las historiografías de Koyré y del propio Febvre. ${ }^{8}$ Se ha visto en la obra de François Jacob, La logique du vivant (1970), una clara confluencia entre la historia social del cuerpo, al estilo de los Annales, y la historia de las ciencias biológicas, al estilo de Canguilhem. ${ }^{9}$ Un artículo publicado en la revista Annales ESC (1973), identificaba en los trabajos de la epistemología histórica francesa, la mejor teorización posible del saber histórico en curso. ${ }^{10}$ Sobre este trasfondo, hace casi treinta años, intenté por mi parte trazar el cuadro general de las convergencias, divergencias e isomorfismos, entre la historia social de los Annales y la tradición de la historia epistemológica de las ciencias. ${ }^{11}$

Sin embargo, al mismo tiempo que se subrayaba la proximidad y el paralelismo entre ambos estilos historiográficos, se insistía en el desconocimiento y en los reproches mutuos. En este punto hay que referirse a dos acontecimientos significativos. El primero lo constituyó la publicación, en 1975, de un número monográfico de Annales ESC, dedicado al asunto de la Historia de las Ciencias. En la presentación, redactada por Jacques Revel (1975: 933), ${ }^{12}$ se mencionaba la "ignorancia compartida" de historiadores generales e historiadores de las ciencias, acerca de lo que hacía cada uno. Se lamentaba el desconocimiento, por parte de los historiadores de los Annales, de una "tradición epistemológica original" francesa. Se insistía también en el confinamiento de los historiadores de las ciencias dentro del puro análisis interno del discurso, mostrándose poco interesados por las condiciones sociales de la actividad científica. No puede decirse, sin embargo, que la presencia de la epistemología histórica francesa fuera muy nutrida dentro del mencionado monográfico. Salvo un artículo de Claire Salomon-Bayet (1975), ${ }^{13}$ discípula de Canguilhem, y otro de Michel Serres, ${ }^{14}$ sobre historia de la cosmología, además de la recensión de un libro de Koyré (Barret-Kriegel 1975), ${ }^{15}$ el resto quedaba fuera de esta tradición gala. En cambio, figuraban algunos de los más ilustres representantes de la herencia anglosajona, como Thomas S. Kuhn y Joseph Needham.

El otro suceso relevante en este recordatorio del desconocimiento recíproco entre historiadores de Annales y epistemólogos, tuvo lugar a comienzos de la década de los ochenta, en una Journée dedicada a explorar la relación entre "Histoire des sciences et des mentalités". Las intervenciones de ese coloquio fueron publicadas en 1983 en la Revue de Synthèse. Por el lado de Annales participaron historiadores tan reconocidos como Jacques Le Goff y Roger Chartier; en el caso de los epistemólogos de tradición francesa, el representante principal en el debate fue Yvette Conry, discípula de Georges Canguilhem y estudiosa de la historia del lamarckismo y el darwinismo en Francia. Los dos primeros subrayaron la "ignorancia mutua", ${ }^{16}$ pero Chartier, ${ }^{17}$ insistió sobre todo en el beneficio que habría supuesto para los

7 G. Massicotte, L'bistoire problème. La méthode de Lucien Febure (Paris/ Montréal: Edisem Maloine, 1981), 27-32.

${ }^{8}$ Pietro Redondi, "Science moderne et histoire des mentalités. La rencontré de Lucien Febvre, Robert Lenoble et Alexandre Koyré," Revue de Synthèse, [vol.] 111-12, (1983): 339-340 (309-332).

9 Jacques Le Goff, "L'histoire nouvelle," en La nowvelle histoire, dir. Jacques Le Goff, Roger Chartier et Jacques Revel (Paris: CEPL, 1978), 210-241, 232-233.

${ }_{10}$ Blandine Barret-Kriegel, "Histoire et politique ou l'histoire, science des effets," Annales ESC, [vol.] 28, 5, (1973): 1439-40 (1437-1462).

${ }^{11}$ F. Vázquez García, El análisis arqueológico-genealógico de Michel Foucault en el panorama de la historiografía francesa contemporánea. La revolución foucaultiana del saber histórico (Cádiz, Universidad de Cádiz, tesis doctoral inédita: 1987 ) 158-189.

https://www.academia.edu/5650454/El An\%C3\%A1lisis arqueol $\%$ C3\%B3gicogeneal $\% \mathrm{C} 3 \% \mathrm{~B} 3$ gico de Michel Foucault en el panorama de la historiograf $\% \mathrm{C} 3 \% \mathrm{ADa}$ francesa c ontempor $\% \mathrm{C} 3 \% \mathrm{~A} 1 \mathrm{nea}$. La revoluci $\% \mathrm{C} 3 \% \mathrm{~B} 3 \mathrm{n}$ foucaultiana del saber hist $\% \mathrm{C} 3 \% \mathrm{~B} 3$ rico tesis doct oral_completa 1987 [consultado el 8 de julio de 2015].

12 Jacques Revel, "Présentation," Annales ESC, [vol.] 30, 5 (1975): 933 (933-934).

13 Claire Salomon-Bayet, "L'institution de la science: un exemple du XVIIIe siècle," Annales ESC, [vol.] 30, 5 (1975): (1028-1044).

14 Michel Serres, “Le retour éternel,” Annales ESC, [vol.] 30, 5 (1975): (999-1006).

15 Blandine Barret-Kriegel, "Koyré, A.: Études d'histoire de la pensée scientifique," Annales ESC, [vol.] 30, 5 (1975): 1939-40 (1124-1127).

16 Jacques Le Goff, "Histoire des sciences et histoire des mentalities," Revue de Synthèse, [vol.] 111-12 (1983): 497 (407-416).

${ }^{17} \mathrm{El}$ texto de Roger Chartier, "Histoire intelectuelle et histoire des mentalities. Trajectoires et questions," Revue de Synthèse, [vol.] 111-12, 295-96 (277-308) es la versión francesa de un capítulo de libro publicado originalmente en inglés en 1982. 
historiadores de las mentalidades conocer los hallazgos de la epistemología histórica. Conry ${ }^{18}$ por su parte se refirió a la "ceguera patente" de los miembros del grupo de Annales.

Sería injusto, no obstante, dirigir sólo las acusaciones hacia los integrantes de la escuela de los Annales. Hoy sabemos bien que los historiadores de las ciencias tampoco fueron muy receptivos con las aportaciones de la historia social. Alexandre Koyré, por ejemplo, filósofo de formación, explicaba las revoluciones científicas - en el terreno de la astronomía o de la mecánica, privilegiando el cambio puramente interno, teórico; esto es, enfatizando la transformación de los supuestos ontológicos y minusvalorando los factores técnicos y las condiciones sociales. ${ }^{19}$ Bachelard, por su parte, cuyas obras principales vieron la luz entre las décadas de 1930 y 1950, seguía manteniendo en esa época una visión decimonónica de la "historia general", más próxima a la "historia episódica" que a la "historia problema" de Febvre y Bloch. A su entender, la historia - "historia de los imperios y de los pueblos" $20_{-}$ pertenecía al campo de la "cultura literaria", ${ }^{21}$ de "estructura pobre", ${ }^{22}$ y no tenía por ello sentido que pretendiera adquirir un estatuto científico.

¿Por qué esta convergencia y a la vez esta falta de reconocimiento recíproco entre la historia social de los Annales y la epistemología histórica francesa? Para encontrar una respuesta a esta cuestión ha sido necesario aguardar hasta la publicación de dos importantes trabajos. En primer lugar la tesis doctoral de Enrico Castelli Gattinara (elaborada entre 1985 y 1992), 23 editada en 1998. En segundo lugar, la aparición, diez años más tarde, del libro de Christina Chimisso. ${ }^{24} \mathrm{El}$ primero da cuenta de las raíces intelectuales y en parte institucionales de la convergencia y el desconocimiento recíproco entre las dos corrientes. El segundo, situado en el campo de la sociología de la filosofía, aclara decisivamente la dimensión institucional, pero además señala las condiciones sociales y las connotaciones políticas de un proceso que involucró a dominios disciplinares muy diversos (historia, sociología, filosofía, historia de las ciencias). Ambos, sin embargo no tienen en cuenta la excepción que representa Georges Canguilhem respecto a esa falta de comunicación entre las dos tradiciones.

\section{La excepción Canguilhem y su diálogo con el grupo de los Annales}

¿Por qué se ha ignorado hasta la fecha el diálogo entablado por Canguilhem con los historiadores de los Annales? Ha habido que esperar, en efecto, al redescubrimiento de la obra del filósofo francés desde finales de los años 90,25 para empezar a entrever esta relación. Los estudiosos se dieron cuenta de que la obra de Canguilhem no sólo no comenzaba con la publicación de su tesis doctoral, el Essai sur quelques problèmes concernant le normal et le pathologique (1943), sino que se remontaba a veinte años antes, con la publicación de decenas de artículos y varios libros que habían pasado desapercibidos para la crítica posterior. ${ }^{26}$ La edición de este material en el primer volumen de las Oeuvres Complètes (2011) ${ }^{27}$ y la apertura, en esa misma

18 Yvette Conry, "Combat pour l'histoire des sciences: lettre ouverte aux historiens des mentalities," Revue de Synthèse, [vol.] 111-12, 365 (363-406).

19 Pietro Redondi, "Science moderne," 328.

${ }^{20}$ G. Bachelard, La actividad racionalista de la física contemporánea (Buenos Aires: Siglo Veinte, 1975), 33.

${ }^{21}$ G. Bachelard, La philosophie du non (Paris: PUF, 1983), 132.

22 G. Bachelard, La actividad, 15.

${ }^{23}$ E. Castelli Gattinara, Les inquiétudes de la raison. Épistémologie et histoire en France dans l'entre-deux-guerres (Paris: Vrin, EHESS, 1998).

${ }^{24}$ C. Chimisso, Writing the bistory of the mind. Philosophy and science in France, 1900 to 1960s (Aldershot: Ashgate Pub., 2008).

25 Francisco Vázquez García, "Redescubriendo a un filósofo híbrido: Georges Canguilhem," Asclepio. Revista de Historia de la Medicina y de la Ciencia, [vol] 66, 2 (2014): 65, http://dx.doi.org/10.3989/asclepio.2014.29 [consultado el 9 de julio de 2015].

26 Para esto fue crucial la exhaustiva compilación bibliográfica ("Critical Bibliography”) realizada por el discípulo de Canguilhem, Camille Limoges en François Delaporte, A vital rationalist. Selected writings from Georges Canguilhem (New York: Zone Books 1994), 385-481.

27 El plan de las Oeuvres Complètes abarca cinco tomos y recoge toda la obra publicada por el filósofo. Hasta la fecha han visto la luz dos volúmenes: G. Canguilhem, Écrits philosophiques et politiques 1926-1939. 
época, de los Fonds Canguihem en el CAPHÈS (École Normale Supérieure), ${ }^{28}$ albergando una cantidad considerable de cursos, conferencias y documentación inédita, ha trastocado por completo la imagen de este pensador. Se ha hablado por ello de un "Canguilhem perdido" 29 y de un "Canguilhem antes de Canguilhem". ${ }^{30}$ Este aparece como un filósofo sustantivo, donde priman las cuestiones de orden ético y político sobre los asuntos de epistemología e historia de las ciencias, a los que Canguilhem habría accedido en una fase tardía de su carrera. ${ }^{31}$

Un examen comprehensivo de esas nuevas fuentes inadvertidas o sólo recientemente accesibles, hace insostenibles ciertas actitudes y ciertos pronunciamientos. Ya no puede lamentarse, por ejemplo, la falta de comunicación entre epistemólogos e historiadores de Annales, añorando una integración entre la obra de Canguilhem y la de Fernand Braudel ${ }^{32} \mathrm{O}$ aludir a la dificultad de imaginar una colaboración entre la historia social de Febvre, de un lado, y la epistemología histórica de Bachelard y Canguilhem, del otro. ${ }^{33}$ Tampoco es exacto decir que el proyecto arqueogenealógico de Foucault constituye el primer encuentro entre las dos corrientes concernidas. ${ }^{34}$ Ese contacto ya fue establecido por Canguilhem; hoy sabemos que si el discípulo pudo retomarlo fue en cierto modo porque tomó impulso a partir del nexo forjado por el maestro.

Canguilhem, en efecto, conoció muy bien la obra de la primera generación de los Annales (Halbwachs, Febvre y Bloch) y mantuvo estrecha relación, personal e intelectual, con el sociólogo Georges Friedmann, ${ }^{35}$ uno de los miembros destacados del Comité de Redacción de la revista en la siguiente generación, tras la Segunda Guerra Mundial. El filósofo de Castelnaudary era plenamente consciente, al menos desde 1931, de la existencia, no de un "grupo de los Annales", sino de un "equipo de Estrasburgo", 36 al que alude en más de una

Oeuvres Complètes, tome I (Paris: Vrin, 2011) y G. Canguilhem, Résistance, philosophie biologique et histoire des sciences, 1940-1965. Oeuvres Complètes, tome IV (Paris: Vrin, 2015).

28 Consultamos los Fonds Canguilhem durante una estancia realizada en mayo de 2015, en el curso del año sabático que me concedió la Universidad de Cádiz. Agradezco a su directora Mireille Delbraccio y a los bibliotecarios Natalie Queyroux y Davis Dénechaud, su amable acogida y ayuda para solventar todas mis dudas.

${ }^{29} J$ ean François Braunstein, “À la découverte d'un 'Canguilhem perdu'," en Écrits philosophiques et politiques 1926-1939. Oeuvres Complètes, tome I, Georges Canguilhem (Paris: Vrin, 2011), 101-137.

30 Jean François Braunstein, "Canguilhem avant Canguilhem," Revue d'bistoire des sciences, [vol.] 53, 1 (2000): (9-26).

31 Camille Limoges, "L'épistémologie historique dans l'itineraire intellectuel de Georges Canguilhem," en Epistemology and History from Bachelard and Canguilhem to today's history of science (Berlin: Max Planck Institute for the History of Science, 2012), 53-66, https://www.mpiwg-berlin.mpg.de/Preprints/P434.PDF [consultado el 7 de Julio de 2015] y Camille Limoges, "Introduction. Philosophie biologique, histoire des sciences et interventions philosophiques. Georges Canguilhem 1940-1965," en Résistance, philosophie biologique et histoire des sciences, 1940-1965. Oeuvres Complètes, tome IV, Georges Canguilhem (Paris: Vrin, 2015), 7-49, 46-47

32 Jonathan Hodge, "Canguilhem and the history of biology," Revue d'Histoire des Sciences, [vol.] 53, 1 (2000): 78 (65-82).

33 Cristina Chimisso, "The tribunal of philosophy and its norms: history and philosophy in Georges Canguilhem's historical epistemology," Studies in History and Philosophy of Biological and Biomedical Sciences, [vol.] 34 (2003): 309 (297-327).

${ }^{34}$ L. Paltrinieri, L'experience du concept. Michel Foucault entre épistémologie et histoire, (Paris, Publications de la Sorbonne: 2012), 17.

35 Georges Canguilhem, "Georges Friedmann, Leibniz et Spinoza," (1946) en Résistance, 233-240; Georges Canguilhem, "Machine et organisme," (1947) en La connaissance de la vie (Paris: Vrin, 1980), 101-127; Georges Canguilhem, "Le vivant et son milieu," (1947) en ibid.,129-154 y Georges Canguilhem, "Milieu et normes de l'homme au travail," (1947) en Résistance, 291-306. Georges Friedmann, verdadero fundador de la sociología del trabajo en Francia, cuyo mentor intelectual fue Lucien Febvre, frecuentó en Toulouse junto a Canguilhem el círculo del jurista italiano antifascista Silvio Trentin. Desde julio de 1940 y en este entorno, el sociólogo y el filósofo participaron en reuniones clandestinas que fueron el embrión de su implicación en la Resistencia, Camille Limoges, "Introduction", 10; Jean-Pierre Amalric, "Terribles et grandioses: les années toulousaines de Georges Friedmann (1940-1945)," en Georges Friedmann. Un sociologue dans le siècle 1902-1977, dir. Pierre Gremion et Françoise Piotet (Paris: CNRS Éditions, 2004), 29-49 y Georges Friedmann, “Témoignage de Georges-Philippe Friedmann recueilli par Madame Merlat (1946)," en Ibid., 81-89. Canguilhem siempre se expresó en términos elogiosos sobre la obra de Georges Friedmann.

36 Georges Canguilhem, "Sociologie. Les causes du suicide," (1931) en Écrits philosophiques, 375-382, 379. A edad avanzada, Canguilhem era consciente de la heterogeneidad de esa "escuela": “je crois pouvoir confirmer que le 'cercle' -plus encoré que l'école proprement dite- des Annales, était composé de 
ocasión, ${ }^{37}$ haciendo más tarde referencia, tras la trágica desaparición de Marc Bloch y Maurice Halbwachs, a los trabajos de "Lucien Febvre y de su escuela". ${ }^{38}$ El equipo, por tanto, se define primero por su emplazamiento en la Faculté de Lettres de la Universidad de Estrasburgo, formado por los tres estudiosos mencionados, a los que se añade la figura del psicólogo bergsoniano, Charles Blondel. ${ }^{39}$ Se da la circunstancia de que Canguilhem fue también profesor en ese centro desde noviembre de 1941, algo que marcó su trayectoria decisivamente, ${ }^{40}$ y donde la presencia de los fundadores de Annales estaba aún en la atmósfera, ${ }^{41}$ pero para entonces estos ya habían cambiado su destino académico.

Por otra parte, desde la perspectiva canguilhemiana, el grupo de Estrasburgo estaba indisociablemente unido por su inspiración y planteamiento a otra escuela, la de geografía humana fundada por Vidal de la Blache a comienzos del siglo XX.42 Esta recepción de la escuela vidaliana en la obra de Canguilhem, ha sido examinada en diversos trabajos. ${ }^{43}$ Lo que según el filósofo distingue a la sociología de Halbwachs respecto a la durkheimiana, haciéndole ganar en lucidez y profundidad científica, es la incorporación crucial del concepto de "géneros de vida", tomado de la geografía vidaliana. ${ }^{44}$ Los trabajos de Febvre y de Bloch más citados y utilizados por Canguilhem, aunque como veremos más adelante, no sean los únicos que conocía, son los que se encuadran en la estela de esa misma tradición de geografía humana: La terre et l'évolution bumaine $(1922)^{45}$ en el primer caso y Les caractères originaux de l'bistoire rurale française (1931), ${ }^{46}$ en el segundo. De hecho, la historia tal como la entienden los Annales y la geografía vidaliana representan para el filósofo dos caras de una misma moneda. ${ }^{47}$

professionnels dont le consensus sur les normes et méthodes de recherche n'entrainait nécessairement l'unanimité sur les voies á explorer et l'utilisation des résultats sur le terrain politique" (Carta manuscrita de Georges Canguilhem a Francisco Vázquez García, 5 de enero de 1989).

${ }^{37}$ Georges Canguilhem, "Maurice Halbwachs (1877-1945)," (1947) en Résistance, 275-289, 277.

38 Georges Canguilhem, "Le vivant et son milieu," 142.

${ }^{39}$ Georges Canguilhem, "Maurice Halbwachs," 277-278.

40 Claude Debru, "Introduction. Présence de Georges Canguilhem," en Philosophie et Médecine. En hommage á Georges Canguilhem, ed. Anne Fagot-Largeault y otros (Paris: Vrin, 2008), 7-9, 8.

${ }^{41}$ En noviembre de 1941 Canguilhem sustituyó como profesor a Jean Cavaillès (trasladado a París) en la Faculté de Lettres de Strasbourg (desplazada a Clermont Ferrand durante la ocupación). Tras la Liberación y desde el verano de 1945, permaneció hasta 1948 como profesor en el mismo centro, pero ya en Strasbourg. Febvre dejó Strasbourg por París (Collège de France) en 1933 y Bloch hizo lo propio (Faculté de Lettres de la Sorbonne) en el verano de 1936. Este, sin embargo, tras su periplo de soldado y en medio de las leyes antisemitas de Vichy, tuvo que regresar a la Universidad de Strasbourg (en Clermont Ferrand) en septiembre de 1940, C. Fink, Marc Bloch. Una vida para la historia (Valencia: Universitat de Valencia, 2004), 237-243. En otoño de 1941, fue destinado a Montpellier, de modo que nunca llegó a ser compañero de Canguilhem en la misma Universidad, Ibid., 255.

42 A. Buttimer, Sociedad y medio en la tradición geográfica francesa (Barcelona: Oikos-tau, 1980); P. Claval (dir.), Autour de Vidal de la Blache. La formation de l'école française de Géographie, (Paris: CNRS Éditions) y V. Berdoulay, La formation de l'école française de géographie (Paris: Éditions du CTHS, 2008).

${ }^{43}$ G. Le Blanc, La vie humaine. Anthropologie et biologie chez. Georges Canguilhem (Paris: PUF, 2002), 184-190; Michèle Cammelli, "Présentation á Le fascisme et les paysans," en Georges Canguilhem, Écrits philosophiques, 515-533, 526-533 y Laurence Cornu, "Le parti pris humain," en La formation de Georges Canguilhem. Un entre-deux-guerres philosophique, dir. Louis Ferté, Alain Jacquard et Patrice Vermeren (Paris: Hermann, 2013), 87-111.

${ }^{44}$ Georges Canguilhem, "Sociologie. Les causes du suicide," 378.

45 En el curso inédito, impartido por Canguilhem en 1939-40 en el Institut Agronomique de Toulouse, titulado "L'homme et le sol", se recurre a esta obra para exponer los prejuicios del determinismo geográfico, citando una frase de Febvre recogida también en otros textos de Canguilhem, Ibid., 379: "l'homme est un agent géographique" (G.C. 10.4, f. 2). Citamos con la notación y paginación tal como aparece en los Fonds Canguilhem del CAPHÈS. En "Le vivant et son milieu", 139, el filósofo remite a esa misma obra de Febvre para conocer la historia del determinismo geográfico como idea.

${ }^{46}$ Esta obra desempeñó un papel fundamental en Georges Canguilhem, Le fascisme et les Paysans (1935) en Écrits philosophiques, 542-43. Bloch, del mismo modo que el geógrafo Roger Dion, mostraba la variedad de géneros de vida rurales en Francia, desacreditando así las simplificaciones de la izquierda y de la derecha acerca de la mentalidad y la existencia campesinas. Veinte años después, en su lección inaugural como director del Institut d'Histoire des Sciences et des Techniques (1955), Canguilhem remitía a la misma obra de Bloch para mostrar el parentesco etimológico entre "error" y la actitud de los campesinos desviándose de la línea recta y labrando al través G.C. 13.1.1, f. 24.

47 "Ya hayan abordado la geografía por la historia o, al contrario, la historia por la geografía, todos están de acuerdo en investigar en las técnicas colectivas de explotación, en sistemas agrícolas, los principios de explicación de las estructuras de paisajes que, los antiguos geógrafos habían atribuído a menudo a los 
La noción de "géneros de vida" traduce la idea de que el paisaje, el suelo, el espacio, en suma, es un producto histórico. "La geografía se explica por la historia"48 y no al revés, como sostenía la escuela determinista liderada por Ratzel. La geografía está toda ella "penetrada por la historia". ${ }^{49}$ Esto significaba que el medio (suelo, fauna, vegetación) es producto de la actividad humana, del hombre como factor geográfico. Esa actividad es la que engloba la noción de "géneros de vida", que incluye la acción técnica, los sistemas de civilización (normas religiosas, jurídicas, económicas, etc) y el trabajo. Al alterar así su entorno, transformándolo, el hombre modifica al mismo tiempo su propio cuerpo. Por eso, y aquí Canguilhem remite a los trabajos de Halbwachs ${ }^{50}$ y de Maximilien Sorre, ${ }^{51}$ las características biológicas de la especie humana (estatura, longevidad, natalidad, morbilidad, presión arterial, etc) expresan al mismo tiempo normas sociales, elecciones civilizatorias ligadas a un "género de vida" históricamente cambiante. No se trata, frente a la tesis antropométrica de Quêtelet, de puros fenómenos biológicos manifiestos en promedios estadísticos sino que expresan modos de vida, es decir opciones de valor entre varias posibles, compatibles con las mismas condiciones biológicas de existencia. ${ }^{52}$

La presencia de los geógrafos de la escuela vidaliana en la obra de Canguilhem es constante, al menos desde comienzos de la década de 1930 hasta los primeros años de la de 1960. Cita y utiliza a Vidal de la Blache, ${ }^{53}$ Jean Brunhes, ${ }^{54}$ Henri Baulig, ${ }^{55}$ Maximilien Sorre, ${ }^{56}$ Daniel Faucher, ${ }^{57}$ Roger Dion, ${ }^{58}$ y menciona a Albert Demangeon ${ }^{59}$ y Gaston Roupnel. ${ }^{60}$. Algo

solos efectos necesarios del relieve y el clima", Georges Canguilhem, "Vignes et vins de France," (1961), en Résistance, 966 (todas las traducciones del francés incluidas en el artículo son nuestras)

48 "L'homme et le sol" (1939-40), G.C. 10.4, f. 5.

${ }^{49}$ Curso "Les normes et le normal", impartido en la Universidad de Estrasburgo (desplazada a Clermont Ferrand), 1942-43, G.C. 11.2.2, f. 44.

${ }^{50}$ Canguilhem, apoyándose en Halbwachs, muestra que normas vitales como la longevidad y la edad de fallecimiento, traducen también una normatividad social, vinculada a través de la higiene y las condiciones de trabajo con factores como la clase y la profesión, Georges Canguilhem, "Essai sur quelques problèmes concernant le normal et le pathologique," (1943) en Le normal et le pathologique (Paris: Vrin, 1972), 3-167, 99-104. Lo que no se conoce tanto es la elaboración de ese argumento en un curso anterior que ya hemos citado: "Les normes et le normal", G.C. 11.2.2., ff. 41-46. Por otra parte, el primer volumen que abría en 1952 la colección, una antología de textos para uso de estudiantes, denominada "Textes et documents philosophiques", dirigida por Canguilhem, se titulaba Besoins et tendances. Incluía dos textos de Maurice Halbwachs sobre la función social de la comida familiar entre los obreros, y sobre la relación entre composición de las comidas y nivel social de vida, respectivamente, Georges Canguilhem, "Besoins et tendances. Textes choisis et présentés par G. Canguilhem," en Résistance, 437-524, 470-473.

51 Les fondements biologiques de la géographie humaine (1943) de Maximilien Sorre, constituye una referencia fundamental de Canguilhem, pues muestra la "labilidad" de las constantes fisiológicas, a partir de los factores que constituyen los "géneros de vida", como sucede con los "regímenes alimentarios": Georges Canguilhem, "Essai sur quelques problèmes," 105, 110-111. El caso, estudiado por Sorre, de la desecación de las zonas pantanosas de Sologne y Brève y su efecto en el crecimiento de la talla media de los habitantes, aparece frecuentemente mencionado por Canguilhem (Jean François Braunstein, "Jeunesse de Georges Canguilhem," en La formation de Georges Canguilhem, 163), así como otros análisis geohistóricos de Sorre (por ejemplo el efecto combinado del régimen alimentario inca y de las condiciones de trabajo establecidas por los conquistadores españoles): "L'homme et le sol" (1939-40), G.C. 10.4, f. 1; ; "Les normes et le normal" (1942-43), G.C. 11.2.2, f. 44; "Normal et pathologique, norme et normal" (1962-63), G.C. 15.1, f. 51; "La relativité des normes", Conferencia impartida en el Collège Philosophique (21 dècembre 1950), G.C.24.9.6, ff. 7-8. En Besoin et tendances, Canguilhem incluía un fragmento de Max Sorre sobre "Geografía de los regímenes alimentarios", Georges Canguilhem, "Besoins et tendances," 469-470.

52 Georges Canguilhem, "Essai sur quelques problèmes," 114; Canguilhem, "Normal et pathologique, norme et normal", curso impartido en la Sorbona 1962-63, G.C. 15.1, f. 51.

53 Georges Canguilhem, "Sociologie. Les causes du suicide," 379; "L'homme et le sol" (1939-40), G.C. 10.4, f. 2; 1943: 102; 1947b: 142; 1961: 966. En Besoin et tendances, Canguilhem incluía un fragmento de Vidal de la Blache sobre la relación entre el tipo de comida y el género de vida, Georges Canguilhem, "Besoins et tendances," 467-468.

${ }^{54}$ Canguilhem, "L'homme et le sol" (1939-40), G.C. 10.4, ff. 1-7.

55 Georges Canguilhem, "Histoire de la science," (1959), en Résistance, 886.

56 Vid. Supra, nota L.

57 Georges Canguilhem, "Le travail et les techniques," (1949), 343-347; Georges Canguilhem, "Vignes et vins," 966.

${ }^{58}$ Georges Canguilhem, Le fascisme, 542; Georges Canguilhem, "Vignes et vins ," 966-970. 
similar sucede con las referencias al equipo de Estrasburgo. ¿Qué sentido tiene el diálogo con esta tradición geohistórica dentro de la trayectoria intelectual de Canguilhem?

\section{La escuela geográfica y el equipo de Estrasburgo en la trayectoria intelectual de Canguilhem}

En el curso de una entrevista concedida poco antes de su muerte, Canguilhem relacionó el interés por la geografía, y en particular por la geografía rural, con su procedencia campesina y con su experiencia directa de las faenas agrícolas y ganaderas: "si yo no hubiese cursado medicina, es posible que me hubiese orientado hacia la geografía agrícola, lo que hoy finalmente se denomina 'ecología"'. ${ }^{61}$ Canguilhem inició sus estudios médicos siendo profesor de filosofía en el liceo Fermat, de Toulouse, en 1936. Como declaró en la mencionada entrevista, la decisión de estudiar Medicina obedecía al deseo de "añadir a lo que hasta entonces había adquirido de conocimientos librescos en filosofía, algunos conocimientos de experiencia, como los que podía obtener de la enseñanza de la medicina". ${ }^{62}$ Sin embargo, en esta exigencia de involucrarse en "problemas humanos concretos", 63 el interés por la geografía precedió, en el tiempo, a su vocación médica. ${ }^{64}$ En la recensión que publicó en 1961, de una obra de Roger Dion, ${ }^{65}$ Canguilhem contraponía también el saber "libresco" a la lectura del paisaje practicada por los geógrafos.

El encuentro con la geografía y con los trabajos de la "escuela de Estrasburgo" debe situarse por tanto entre 1930 y $1936,{ }^{66}$ esto es, en el tránsito de una filosofía intelectualista, marcada por las enseñanzas de Alain y asentada en el dualismo kantiano que contraponía espíritu y mundo, hacia el vitalismo. Este paso, explorado con competencia por diversos estudios recientes, ${ }^{67}$ no fue abrupto ni inmediato. Por otro lado, el tránsito de la filosofía del espíritu a la filosofía de la vida, pasó por una etapa intermedia, que podría calificarse como filosofía de la "tierra". La tierra, el paisaje, no como una realidad inerte sino como un producto de la acción humana, y en particular de la actividad técnica, una idea encarnada en la noción de "géneros de vida" que remite al conjunto de acciones por las que el hombre saca provecho de las posibilidades ofrecidas por la naturaleza. ${ }^{68}$ Estas cuestiones de la técnica como creación y exigencia vital que antecede a toda conceptualización científica, de la acción -y de la acción política- como desbordamiento y anticipo de la reflexión teórica, y de la necesidad como raíz vital y normativa de la técnica, ocuparon el centro de la agenda filosófica de Canguilhem en la década de 1930. Ahí se inscribe su atención a la obra de los geógrafos vidalianos y de los historiadores y sociólogos de los Annales. El desplazamiento de interés desde la vida humana

\footnotetext{
${ }^{59}$ En Georges Canguilhem, "Sociologie. Les causes du suicide," 379, menciona Le Rhin. Problèmes d'bistoire et d'économie (1935), obra conjunta de Febvre y Demangeon y Georges Canguilhem, "Le vivant et son milieu," 142.

${ }^{60}$ Georges Canguilhem, Le fascisme, 542; Georges Canguilhem, "Vignes et vins ," 966.

${ }^{61}$ Georges Canguilhem, "Entretien avec Georges Canguilhem" (par François Bing et Jean François Braunstein)," (1995) en Actualité de Georges Canguilhem. Le normal et le pathologique, ed. Jean François Braunstein y otros (Paris: Institut Synthélabo, 1998), 121-135, 133.

62 Ibid., 120.

${ }^{63}$ Georges Canguilhem, "Essai sur quelques problèmes," 7.

${ }^{64}$ Laurence Cornu, "Le parti pris humain," 94-96.

65 Georges Canguilhem, "Vignes et vins ," 965.

${ }^{66}$ Michèle Cammelli, "Présentation," 531-532.

${ }^{67}$ Xavier Roth, "Le jeune Canguilhem, lecteur de Bergson," Dialogues, [vol.] 52 (2013): 635 (625-647); X. Roth, Georges Canguilhem et l'unité de l'experience. Juger et agir 1926-1939 (París: Vrin, 2013), 135-150; Giuseppe Bianco, "The origins of Georges Canguilhem's vitalism: against the anthropology of irritation," History, Philosophy and Theory of the Life Sciences, [vol.] 2 (2013): 245-251 (243-267) y Camille Limoges, "Introduction," 30-31.

${ }^{68}$ Paolo Cesar da Costa Gomes, "Quelques réflexions sur les catégories de la pensé vidalienne," en Autour
} de Vidal de la Blache, 89-97, 93. 
en sus interacciones con el medio, hacia la vida misma entendida como normatividad, no supuso abandonar las referencias a la geografía y a la historia social al estilo de Estrasburgo. ${ }^{69}$

Lo que el filósofo de Castelnaudary tomó de la tradición de Vidal de la Blache y Lucien Febvre no es sólo la crítica del determinismo geográfico y la apuesta por el "posibilismo". Este término, nunca empleado por Vidal de la Blache, ${ }^{70}$ alude a la utilización selectiva, por parte del hombre, de las posibilidades que el entorno le ofrece. El hombre elige y toma partido, no sólo en función de su cultura, sino también de los recursos naturales disponibles. Esta solución, que ha sido juzgada como "neokantiana", ${ }^{71}$ concordaba perfectamente con el trasfondo filosófico del que procedía Canguilhem. El rechazo del determinismo se proyectaba también, y aquí la referencia principal fue Georges Friedmann, en el terreno de la psicología, y más específicamente de la psicología laboral, como una recusación del conductismo inherente a la organización taylorista del trabajo. ${ }^{72}$ Pero la incidencia de Febvre y Bloch en el pensamiento de Canguilhem no sólo se advierte en los motivos del posibilismo geográfico, los géneros de vida, la importancia de la técnica o la cuestión del trabajo. ${ }^{73}$ La misma concepción del saber histórico, que Canguihem elaboró a finales de la década de 1930, es directamente deudora de los fundadores de Annales.

El filósofo fue consciente desde primera hora de lo que suponía la empresa de Febvre y Bloch, "historiadores renovando su disciplina". ${ }^{74}$ En 1939 Canguilhem publicó junto a su colega Camille Planet un Traité de logique et de morale. Aunque en principio, la parte dedicada a "lógica", es decir, a la filosofía de las ciencias, fue redactada por Planet, la totalidad de la obra fue revisada por ambos autores. ${ }^{75} \mathrm{El}$ capítulo VIII de la parte de lógica, consagrado a la "lógica de las ciencias morales", contenía una sección sobre la historia como "descripción del pasado social". ${ }^{76} \mathrm{Si}$ se cruza su lectura con la de un curso inédito, preparatorio del examen de khâgne en el Institut Fermat de Toulouse (1937-38), titulado "Philosophie de l'histoire",77 las coincidencias saltan a la vista, pudiéndose verificar el mismo punto de vista sostenido en el Traité.

En el curso, que es anterior a la edición del tratado, Canguilhem remite a una somera bibliografía que incluye varios artículos de Lucien Febvre, la mayoría publicados en la Revue de Synthèse, algunos de los cuales serán posteriormente incluidos por éste en los Combats pour l'histoire (1953): "Examen de conscience d'une histoire et d'un historien" (1931); "Entre l'histoire á thèse et l'histoire manuel" (1933); "Science et loi: le hasard et l'histoire" (1933), redactado junto a Victor Chapot, y el artículo conjunto de Henri Berr y Lucien Febvre, "History", para la Encyclopaedia of the Social Sciences (1937).

La impronta de Febvre y del impulso renovador de los Annales está presente en estas dos intervenciones de Canguilhem. De entrada se asume la ruptura de los que denomina

\footnotetext{
${ }^{69}$ Frente a lo que señala Yves Schwartz, “Jeunesse d'un philosophe," en Écrits philosophiques, 94-95, no creemos que la temática de la geografía quede relegada en el Canguilhem de madurez, aunque su presencia no sea tan intensa. Por otra parte, nos parece exagerado afirmar, como hace Dominique Lecourt, "La question de l'individu d'après Georges Canguilhem," en Georges Canguilhem philosophe, historien des sciences, Ed. Bibliothèque du Collège International de philosophie (Paris: Albin Michel, 1993), 262-270, 268, que el interés de Canguilhem, mediada la década de los sesenta, por la biología molecular y por la vida en un plano transindividual, suponga "borrar" a Vidal de la Blache, reemplazándolo por Foucault

70 V. Berdoulay, La formation, 214.

71 Ibid., 224.

72 Georges Canguilhem, "Milieu et norms,” 293-299.

73 Por mediación de Georges Friedmann, Canguilhem reseñó en L'Année Sociologique, en 1949 y 1951 , dos libros colectivos que recogían las intervenciones en dos coloquios sobre Le travail et les techniques (celebrado en 1941 en Toulouse) e Industrialisation et technocratie (celebrado en París en 1948). En el primero, al que asistió el propio Georges Canguilhem, "Le travail et les techniques," (1949) en Résistance, 344, elogió la introducción de Febvre (“con su lucidez y su tino acostumbrados") y las ponencias de Marc Bloch y del geógrafo Daniel Faucher, Ibid., 346-47. En el segundo, introducido también por Febvre, comentó muy favorablemente la ponencia impartida por Friedmann (Georges Canguilhem, "Industrialisation et technocratie," (1951), en Résistance, 400).

74 Georges Canguilhem, "Maurice Halbwachs," 278.

75 Xavier Roth, "Présentation á Traité de logique et de morale," en Écrits Philosophiques, 597-630, 624-625.

${ }^{76}$ Georges Canguilhem, Traité de logique et de morale (1939) en Écrits Philosophiques, 764-770.

77 G.C. 10.4.13, 9 folios manuscritos.
} 
"historiadores modernos", con una "historia tradicional" centrada en el papel decisivo desempeñado por las "personalidades importantes", que explicaba los acontecimientos históricos por "decisiones personales". ${ }^{78}$ Este prejuicio, según Canguilhem, procede de proyectar nuestra experiencia íntima de la duración en el tiempo histórico, que es en realidad un tiempo construido. Estas dos ideas; la descalificación de la conciencia de los protagonistas como clave de los sucesos y la consideración del tiempo como un constructo, están en las bases mismas del proyecto de Annales. ${ }^{79}$ Canguilhem combinaba las sugerencias de Febvre con las lecciones que extrajo de dos libros que constituyen su referencia principal en materia de teoría de la historia: las Consideraciones intempestivas (1873-1876) de Nietzsche y la Introducción a la filosofía de la historia. Ensayo sobre los limites de la objetividad histórica (1938), tesis doctoral de su compañero y condiscípulo de Alain, Raymond Aron. ${ }^{80}$

Esta coalición de recursos intelectuales le permite impugnar la ilusión del viejo objetivismo histórico, de matriz rankeana. Los hechos, como había enfatizado Febvre ${ }^{81}$ en un texto utilizado por Canguilhem, no están dados a la mirada del historiador avisado; son una reconstrucción selectiva realizada a partir de la relación del estudioso con los valores de su época: "por eso hay tantas historias como historiadores"; 82 "es del presente y desde el presente donde una cierta elección significativa fija la importancia de los hechos pasados" 83 . Este planteamiento, inspirado en Weber a través de su recepción en la obra de Aron, converge también con las críticas de Febvre y Bloch a la noción positivista de "hecho histórico". Además, la idea de una historia que parte del presente para esclarecerlo, coincide con la noción de "historia regresiva" forjada por Marc Bloch. ${ }^{84}$

Otro punto de convergencia con los fundadores de los Annales lo constituye el rechazo de la filosofía especulativa de la historia, ${ }^{85}$ "pecado de filósofo, tentación de historiador" 86 , que cae en la ilusión de la fijeza definitiva del pasado. También comparte con Febvre $^{87}$ y Bloch $^{88}$ la crítica a la visión estrecha del documento (ya se ha visto que para Canguilhem el paisaje es un documento de primer orden) que caracterizaba a la escuela "metódica" 89 de Fustel de Coulanges, Monod y Lavisse; la historia no se hace sólo con textos.

Una interesante concordancia de Canguilhem con Febvre y Bloch la constituye su desmarque respecto a la historia trazada de modo teleológico y retrospectivo. En ese género de relato, el presente aparece siempre anticipado germinalmente por el pasado, de modo que éste queda "vaciado de la incertidumbre que lo caracteriza". ${ }^{0}$ La figura que encarna esta historia preñada de ilusión retrospectiva, es la del "precursor". En un manuscrito dactilografiado y datado en 1948, Canguilhem redactó algunos capítulos de lo que debía ser una monografía introductoria al pensamiento de Descartes. ${ }^{91}$ En ese texto y remitiendo explícitamente al libro

\footnotetext{
${ }^{78}$ Georges Canguilhem, Traité, 764-65.

${ }^{79}$ F. Vázquez García, Estudios de teoría y metodología del saber histórico. De la escuela histórica alemana al grupo de los "Annales" (Cádiz: Publicaciones de la Universidad de Cádiz, 1988), 102-104 y 117-120 .

${ }^{80}$ Estas dos obras aparecen mencionadas por Canguilhem en más de una ocasión: Georges Canguilhem, Traité, 766; "Philosophie de l'histoire", curso para la preparación de la khâgne impartido en el Licée Fermat, de Toulouse (enero 1938), G.C. 10.4.13, f. 1 v. y f. 8 v. (aquí se menciona asimismo la tesis complementaria de Raymond Aron, el Essai sur la théorie de l'bistoire dans l'Allemagne contemporaine. La philosophie critique de l'bistoire, 1938) y "Histoire de la philosophie et histoire des sciences", curso impartido en Strasbourg (Clermont-Ferrand), marzo 1945, p. 4. Sobre las tesis de Aron, Georges Canguilhem, "La problématique de la philosophie de l'histoire au debut des années 30," (1988) en Raymond Aron, la philosophie de l'bistoire et les sciences sociales, Alain Boyer y otros, (Paris: Éditions Rue d’Ulm, 2005), 19-32.

${ }^{81}$ L. Febvre, Combats pour l'bistoire (Paris: Armand Colin, 1953), 7-8.

${ }^{82}$ Georges Canguilhem, Traité, 766.

83 "Philosophie de l'histoire", G.C. 10.4.13, f. 2 r.

${ }^{84}$ M. Bloch, Apologie pour l'bistoire ou métier d'bistorien (Paris: Armand Colin, 1993), 96-97.

85 L. Febvre, Combats, 119-143.

86 "Philosophie de l'histoire", G.C. 10.4.13, f. 3 r.

${ }^{87}$ L. Febvre, Combats, 13.

88 M. Bloch, Apologie, 106-111.

89 "Philosophie de l'histoire," G.C. 10.4.13, f. 2 r.

90 "Philosophie de l'histoire," G.C. 10.4.13, f. 1 v. A esa historia sin sentido de la incertidumbre, L.

Febvre, Combats, 102, la denominaba "histoire psittacique" ("papagáyica).

91 "Descartes interrompu...,1948," G.C. 28.1.5.
} 
de Lucien Febvre sobre Rabelais, Le problème de l'incroyance au XVTe siècle (1942), ${ }^{92}$ criticaba la lectura que Maxime Leroy realizaba de Descartes como un librepensador y ateo "avant la lettre". Ponía en tela de juicio la "caza de los precursores". 93

En una segunda ocasión, reseñando la Histoire générale des sciences dirigida por René Taton, Canguilhem ${ }^{94}$ volvía a cuestionar la noción de "precursor", utilizada por algunos de los colaboradores de esa obra. La existencia de "precursores" significaría según el filósofo la negación de la historicidad de los discursos científicos, presuponiendo el carácter eterno de la verdad. Aquí citaba las definiciones de la historia propuestas respectivamente por Marc Bloch ("la historia es la ciencia del cambio") y Lucien Febvre ("la ciencia de los cambios").

\section{Alianzas académicas y espacios políticos compartidos}

Pero el diálogo de Canguilhem con los historiadores del "equipo de Estrasburgo" no se limita a mostrar acuerdos o a tomar prestados argumentos de orden epistemológico. Implica también una connivencia de orden ético y político.

En efecto, Canguilhem compartía con Febvre, Bloch y Halbwachs, la pertenencia a una tradición de pensamiento laico, republicano y dreyfusard, plasmada en intelectuales de izquierdas como Jean Jaurés. ${ }^{95}$ Canguilhem, siendo muy joven, conoció a Halbwachs, cuando el primero participaba en la revista pacifista de Alain, Libres Propos. Halbwachs era hermano de Jeanne Alexander, amiga de Canguilhem dentro del círculo de los alainistas. ${ }^{96}$ El filósofo de Castelnaudary rompió hacia 1936 con las convicciones pacifistas defendidas por su maestro, colaborando desde muy pronto, tras la ocupación alemana, en la construcción de los primeros núcleos de la Resistencia.

Por otro lado, Canguilhem, como Lucien Febvre ${ }^{97}$ ingresó desde su fundación en 1934, por los intelectuales Paul Rivet, Alain y Paul Langevin, en el Comité de Vigilance des Intellectuels Antifascistes (CVIA) ${ }^{98}$ Febvre y Canguilhem estaban próximos a un socialismo no marxista ${ }^{99}$. Una de las funciones principales de esta organización, donde figuraban científicos sociales tan prestigiosos como Lévy-Bruhl y Marcel Mauss, ${ }^{100}$ era la redacción y difusión de libritos - a finales de 1936 se había publicado una docena de ellos, que cuestionaban la doxa transmitida por los medios de comunicación mayoritarios, denunciando el fascismo exterior e interior y su respaldo por parte del capitalismo francés. Editaban asimismo un boletín mensual denominado Vigilance . $^{101}$

Canguilhem redactó uno de esos libritos, titulado Le fascisme et les paysans (1935). Febvre y Bloch, por su parte, firmaron el Manifiesto a los Trabajadores, publicado el 5 de marzo de 1934 y redactado por los fundadores del CVIA, aunque mantenían muchas reservas

92 L. Febvre, Le problème de l'incroyance au XVTe siècle. La religión de Rabelais (Paris: Albin Michel, 1968), 2829. La crítica a la "caza de precursores" también la había podido encontrar Canguilhem en La terre et l'évolution bumaine, cuestionando las supuestas anticipaciones del determinismo geográfico en la obra de Jean Bodin, L. Febvre, La terre et l'évolution humaine (Paris: Albin Michel, 1970), 14-17.

93 Georges Canguilhem, "Maxime Leroy, Descartes, le philosophe au masque," (1929) en Écrits philosophiques, nota 1 (del editor Jean-François Braunstein), 251-52.

94 Georges Canguilhem, "Histoire de la science," 868-869.

95 Sobre la vinculación del muy joven Canguilhem con la tradición dreyfusard, Jean François Braunstein, "À la découverte," 123. Respecto a la adhesión de Bloch y Febvre a la causa de Dreyfus y su admiración por Jaurès, C. Fink, Marc Bloch, 141. Halbwachs como intelectual dreyfusard, en Pascal Ory y Jen François Sirinelli, Les intellectuels en France. De l'affaire Dreyfus à nos jours (Paris: Éditions Perrin, 2004), 55.

${ }^{96}$ Georges Canguilhem, "Maurice Halbwachs," 275, nota 1 (del editor Camille Limoges).

${ }_{97}$ C. Chimisso, Writing the bistory, 89; Michèle Cammelli, "Présentation," 531.

98 Ibid., 516-523.

${ }^{99}$ Canguilhem estuvo próximo al radical-socialismo de Mendès France, Camille Limoges, "Introduction," 24.

100 C. Chimisso, Writing the history, 89.

101 Pascal Ory y Jen François Sirinelli, Les intellectuels, 152-155. 
con el tono demagógico de ese escrito y también respecto a la dirección del CVIA. ${ }^{102}$ Esta organización acabó disolviéndose en 1936, escindida entre los impulsos pacifistas y libertarios, el dogmatismo de los comunistas y la oposición de algunos socialistas a esas derivas. Marc Bloch, como sucedió con Friedmann y Canguilhem, ${ }^{103}$ se decantaría inmediatamente, tras la ocupación, por pasar a las filas de la Resistencia.

En esa atmósfera políticamente convulsa, compartiendo espacios de acción, se sitúa el encuentro de Canguilhem con los fundadores de los Annales. Su adopción de la crítica al determinismo geográfico no tenía sólo un contenido filosófico. Esto se advierte claramente en el curso inédito "L'homme et le sol", impartido en el Instituto Agronómico de Toulouse durante el año académico 1939-40. Después de revisar críticamente, apoyándose en La terre et l'évolution bumaine, la historia del prejuicio determinista en Geografía, Canguilhem aludía al anarquista arrepentido e ideólogo nacionalista y antidreyfusard, presidente de la Liga de Patriotas, Maurice Barrès (1862-1923). ${ }^{104}$ Este publicó en 1897 Les déracinés, donde se retrataban las consecuencias nefastas de la educación filosófica republicana, sustentada en el universalismo kantiano, promotora de un racionalismo abstracto y de ciudadanos sin raíces, antipatriotas. ${ }^{105}$

En el curso mencionado, Canguilhem utilizaba las críticas de Febvre y Vidal de la Blache contra el determinismo del suelo y de la sangre. Barrès buscaba en el "instinto y la tierra"106 los valores orientadores de la vida. Pero la nueva geohistoria daba un desmentido a la predestinación hereditaria de la raza ${ }^{107} \mathrm{y}$ al fatalismo del medio y de las "fronteras naturales"108 que entonces, ${ }^{109}$ en la estela de Haushofer hacía furor entre los teóricos del Lebensraum ${ }^{110}$ y en el campo de la demografía. ${ }^{111}$ Canguilhem ponía así al descubierto sus cartas políticas contrarias al nacionalismo y a la ideología jerárquica de las razas.

Esta vertiente política de las intervenciones filosóficas de Canguilhem aun resultan más evidentes en Le fascisme et les paysans. El fascismo esencializaba al campesino, convirtiéndolo en depositario de los valores de la raza y consagrándolo como núcleo de autenticidad incontaminada. ${ }^{112}$ Por su parte, el marxismo dogmático que imperaba en las

102 C. Fink, Marc Bloch, 178-179.

103 Halbwachs, excluido del profesorado por las leyes raciales de Vichy, fue encarcelado por la participación de su hijo en la Resistencia. Murió de inanición en el campo de concentración de Buchenwald, en 1945, A. Becker, Maurice Halbwachs, un intellectuel en guerres mondiales 1914-1945 (Paris: Agnès Viénot, 2003).

104 "L’homme et le sol" (1939-40), G.C. 10.4, ff. 8-11. La confrontación con Barrès se remonta a la juventud de Canguilhem 1930: 306-311.

${ }^{105}$ J. L. Fabiani, ): Les philosophes de la république (Paris: Les éditions de Minuit, 1988), 112-113

106 "L'homme et le sol" (1939-40), G.C. 10.4, f. 8.

107 En L. Febvre, La terre, 125-126 se encuentra una crítica de la noción de raza. Canguilhem se ocupa también con detalle de ese concepto en el mencionado curso, "L'homme et le sol" (1939-40), G.C. 10.4, ff. 12-15. Este recurso al material inédito nos permite desmentir la tesis de Robert Bernasconi, "The racial politics of life itself: Goldstein, Uexküll, Canguilhem and Fanon," en The care of life. Transdisciplinary perspectives in bioethics and biopolitics, ed. Miguel de Beistegui, Giuseppe Bianco y Marjorie Gracieuse (London, New York: Rowman and Littlefield, 2015), 121-133, 125, según la cual Canguilhem habría evitado pensar el problema de la "raza" en la historia de la biología y de la psicología.

108 L. Febvre, La terre,325-332.

${ }^{109}$ Como ha señalado Michèle Cammelli, "Présentation," 531-532, desde marzo de 1934, Lucien Febvre dirigió la edición del tomo VII de L'Encyclopédie française consagrada a L'espèce bumaine, publicado en mayo de 1936, justo después de la victoria del Front Populaire de Léon Blum. Halbwachs participó en este proyecto que pretendía oponerse al reduccionismo biologista de corte fascista en el terreno demográfico. De este modo, la teoría de los géneros de vida aparecía como "un véritable levier théorique de l'antifascisme" (532).

110 Holger H. Herwig, "Geopolitik: Haushofer, Hitler and Lebensraum”, Journal of Strategic Studies, [vol] 22, 23 (1999): (218-241).

111 Michèle Cammelli, "Présentation," 532-533.

112 En una ponencia presentada en 1939 durante un Congreso celebrado en Bucarest, Marc Bloch impugnaba la supuesta "autenticidad" del campesino de raza alemana, defendida por la sociología agraria nazi. En su obra de historia rural, Bloch insistió reiteradamente en la multiplicidad de los orígenes y en la inexistencia del "campesino francés" en singular, Michèle Cammelli, "Présentation," 533. Aunque sin el componente biologicista y en una forma sublimada, este discurso de la "autenticidad" de la vida campesina no es ajeno, como mostró T. W. Adorno, La ideología como lenguaje. La jerga de la autenticidad (Madrid: Taurus, 1992), al pensamiento de Heidegger. 
organizaciones partidarias, concebía el campesinado como una clase homogénea, unificada por los mismos intereses. Los comunistas franceses de la época, asumiendo este concepto unitario, pretendían aplicar en el país galo las mismas recetas colectivizadoras desplegadas por Stalin en la Unión Soviética. ${ }^{113}$

Frente a estas simplificaciones y con vistas a prevenir el reclutamiento del campesinado francés en las filas de la ligas agrarias parafascistas que se estaban organizando, Canguilhem recurrió a los trabajos de la geografía agrícola, en particular los de Marc Bloch, Roger Dion y Gaston Roupnel. Lo que caracterizaba a la población y al paisaje rural galos era su diversidad, con la contraposición entre los "géneros de vida" (hábitat, cultura, técnicas, división de las tierras, tipos de agricultura, concentración demográfica) del nordeste y del sur, como contraste principal. ${ }^{114}$

Por otro lado, el campesino francés se convirtió en propietario de sus tierras desde la Revolución Francesa. Lo que la modernidad había traído consigo era la desposesión y pérdida de independencia de la población agraria: respecto a los medios de transporte, la centralización industrial (a través de la electrificación) y la comercialización a gran escala (dependencia de la burocracia, de los intermediarios y de las compañías emplazadas en las ciudades). En esas condiciones, la ideología de la colectivización propagada por socialistas y comunistas sólo conducía a enajenar el mundo campesino, poniéndolo a merced de las iniciativas más reaccionarias.

Este carácter doble, a la vez teórico y político, del encuentro de Canguilhem con los historiadores de los Annales, presentaba además una tercera vertiente. Se situaba también en un espacio académico, de luchas para preservar fronteras pero también alianzas disciplinares. Esas luchas se conectaban con el reclutamiento y la reproducción de los cuerpos profesionales en las instituciones de enseñanza e investigación. La carrera de Canguilhem, marcada inicialmente por Alain, se abrió paso dentro del campo filosófico, haciendo valer una tradición de filosofía "híbrida", afrontada como historia de la razón (Brunchsvicg, Lèvy-Bruhl, Abel Rey) y maridada con disciplinas extrañas como la historia de las ciencias, la sociología y la antropología. Esto obligaba a tomar distancia de la historia filosófica de la filosofía dominante en la Sorbona, pero también de una filosofía especulativa de la historia que pretendía dictar la ley de los acontecimientos históricos desde el apriorismo de una reflexión pura sobre el acaecer temporal.

Frente a este apriorismo intelectualista de la filosofía académica, al que no era ajeno su maestro Alain, Canguilhem aprendió que el filósofo debía extraer el material de su meditación a partir de disciplinas ajenas a la pureza de los conceptos y de los monumentos filosóficos, saberes concretos y asociados a la práctica y a la experiencia. Uno de estos candidatos era la sociología, pero la vocación imperialista de esta disciplina en su molde durkheimiano, fuertemente objetivista y determinista, amenazaba con introducir el "dogmatismo sociológico en el mercado filosófico", ${ }^{115}$ desvirtuando su identidad.

Se imponía así una estrecha vigilancia de las fronteras filosóficas respecto a la sociología, echando el cierre ante la invasión durkheimiana pero abriendo la puerta ante modalidades más flexibles, como las que representaban Celestin Bouglé116 o Maurice Halbwachs. Algo similar sucedía con la psicología y los peligros del psicologismo. ${ }^{117}$ Un riesgo diferente tenía que ver con las asechanzas de un marxismo dogmático, de partido, cada vez más extendido en la intelectualidad francesa durante la coyuntura dramática de los años treinta. ${ }^{118}$ Frente a ambos dogmatismos, Canguilhem buscó nutrirse de saberes praxeológicos, atentos a los matices y a los contextos, sensibles ante el acontecimiento y respecto a la

\footnotetext{
113 Michèle Cammelli, "Présentation," 533.

114 Georges Canguilhem, Le fascisme, 543-544.

115 Georges Canguilhem, "Sociologie. Les causes du suicide," 380.

116 Giuseppe Bianco, "Life of pain: remarks about negativity and effort in Georges Canguilhem," en The care of life, 156-157, ha señalado las posiciones teóricas de Bouglé contrarias a Durkheim y afines a Canguilhem, de cuya tesis doctoral complementaria fue director .

117 Jean François Braunstein, "La critique canguilhemienne de la psychologie," Bulletin de Psychologie, [vol.] 52, 2/ 440 (1999): (181-190).

118 Yves Schwartz, "Jeunesse," 91-92.
} 
estructuración del medio por la individualidad. En esa dirección transitó primero por la geografía de Vidal de la Blache, de Febvre y de Marc Bloch, y más tarde por la medicina.

En estas luchas académicas, Canguilhem pudo encontrar alianzas valiosas con los intelectuales del grupo de Estrasburgo. A la vez que asentaban su carrera profesional, estos querían romper con la historia episódica dominante en la Universidad, pero recelaban-Febvre más que Bloch- de la vocación expansiva de la sociología en su versión durkheimiana. Frente a la preeminencia normativa de la "conciencia colectiva" y de sus representaciones, defendían la atención a los contextos singulares y a la pluralidad de los "géneros de vida" que modelaban el medio. De ahí su proyección en la Geografía, presente en el sociólogo (Halbwachs) y en los historiadores (Febvre, Bloch) que componían el equipo. Combatían también las abstracciones de la filosofía de la historia y los prejuicios del marxismo vulgar que alentaban visiones esquemáticas del decurso temporal, amenazando la peculiaridad disciplinar del saber histórico.

En sus trayectorias, Canguilhem y los científicos sociales del grupo de Estrasburgo recorrieron senderos paralelos. El primero siguió con atención la empresa intelectual promovida por los segundos, que al mismo tiempo eran sus mayores y pertenecían a una unidad generacional anterior. Por eso se trata de senderos no sólo paralelos, sino encontrados, aunque se bifurquen en direcciones diferentes. La cuestión final es si ese encuentro tuvo efectos duraderos en la singladura posterior de Canguilhem.

\section{Conclusión. Los efectos del encuentro con el grupo de Estrasburgo en la epistemología histórica de Canguilhem}

Mediada la década de 1950, con la publicación de La formation du concept de réflexe aux XVIIe et XVIIIe siècles (1955), tesis doctoral de historia de las ciencias, Canguilhem inició su periplo en lo que más tarde habría de denominarse epistemología histórica. Esta vocación por la historia de las ciencias se hizo más decidida aún a mediados del decenio siguiente, con una impresionante cascada de publicaciones sobre la materia y de comentarios acerca de la obra de Gaston Bachelard. ${ }^{119}$ La inflexión coincidía además con la consagración institucional de nuestro filósofo. Ya en 1948 había sido nombrado Inspector General de segundo grado para la materia de filosofía. ${ }^{120}$ En 1955 dejó el cargo para sustituir a Bachelard como director del Institut d'Histoire des Sciences et des Techniques y catedrático de filosofía e historia de las ciencias en la Sorbona. En los años sesenta llegaría a presidir durante años el tribunal de la Agrégation en filosofía, concentrando un importante capital académico dentro del campo.

En simultaneidad con este viraje hacia la epistemología histórica, las referencias a los geógrafos y a los historiadores de los Annales tendieron a atenuarse. Canguilhem se concentró en un tipo de historia normativa de las ciencias que a primera vista parecía muy alejada de la historia general practicada por los historiadores. ¿Significa esto que el diálogo abierto con los historiadores del grupo de los Annales se interrumpió dejando de surtir efecto sobre la obra posterior de Canguilhem?

Nuestra respuesta es negativa. Lo que dota de un estilo propio a la historia de las ciencias y a la epistemología histórica forjada por Canguilhem, lo que lo distingue de autores aparentemente próximos, como Gaston Bachelard o Alexandre Koyré, deriva precisamente de esa antigua vinculación con el equipo de Estrasburgo.

En un reciente coloquio internacional sobre la epistemología histórica francesa, Pierre-Olivier Méthot ${ }^{121}$ ponía las cosas en su sitio terciando en una controversia acerca de la

119 Camille Limoges, “Introduction,” 25-29.

120 Ibid., 18.

121 Pierre-Olivier Méthot, "On the genealogy of concepts and experimental practices. Rethinking Georges Canguilhem's historical epistemology," en Epistemology and History from Bachelard and Canguilhem to today's bistory of science, Berlin: Max Planck Institute for the History of Science, 2012), 117-143, https://www.mpiwg-berlin.mpg.de/Preprints/P434.PDF consultado el 7 de Julio de 2015. Este trabajo se ha reeditado en Studies in History and Philosophy of Science, [vol.] 44 (2013): (112-123). 
escritura canguilhemiana de la historia de las ciencias. Todo un rosario de comentaristas, siguiendo la estela de los discípulos de Althusser (Macherey, Lecourt, Fichant), había consolidado la idea de que Canguilhem privilegiaba una historia interna de las ciencias, proyectada en el análisis de la formación y transformaciones conceptuales, dejando en un segundo plano tanto el estudio de las técnicas y las prácticas experimentales como el contexto social y cultural donde tenía lugar el trabajo científico.

Esta calificación de "conceptocentrismo" para la epistemología histórica de Canguilhem, ya fuera con fines de encomio o para resaltar su vetustez frente a una epistemología histórica de última generación, más atenta a los aspectos prácticos y sociales de la ciencia, concitó el acuerdo mayoritario de los estudiosos (Rénard, Gutting, Chimisso, Hodge). ${ }^{122}$ Pues bien, frente a esa "concepción heredada", sólo algunas voces aisladas, como las de Grene, Rheinberger o el propio Méthot, habrían defendido que, muy al contrario, lo propio de la epistemología histórica de Canguilhem era su vocación praxeológica. Lejos de desempeñar el papel protagonista, la invención y rectificación de conceptos sólo sería una práctica más, cuya explicación requería para el filósofo de Castelnaudary, ponerla en relación con otras prácticas específicas, ya fueran técnicas o experimentales, todo ello dentro de un determinado contexto cultural. Ajeno al intelectualismo, alérgico al confinamiento en una historia abstracta de las nociones, el enfoque canguilhemiano insertaría el devenir de los conceptos en el decurso concreto de las prácticas y lo usos sociales. ${ }^{123}$ Eso sí, a diferencia de planteamientos como el de Bruno Latour, ${ }^{124}$ Canguilhem recalcaba la singularidad de la actividad científica, regida por una norma que la distinguía de otros quehaceres como la técnica, el arte o la política; esa norma era la pretensión de verdad. Esta voluntad de arraigar la invención y modificación de los conceptos en el plexo histórico de las técnicas y de las prácticas culturales distingue a la historia de las ciencias de Canguilhem respecto a otras modalidades de relato histórico, como las de Bachelard ${ }^{125}$ o Koyré. ${ }^{126}$

Nuestra tesis es que esta singularidad del estilo de Canguilhem, esta voluntad de arraigar el conocimiento en las técnicas y en las formas concretas de existencia cultural y social, sólo es inteligible teniendo en cuenta el encuentro de nuestro autor con los geógrafos de la escuela francesa y con los fundadores de los Annales. Estos le enseñaron a salir del intelectualismo alainista, derivando la racionalidad de los "géneros de vida" en los que aquella está encofrada, educando su sensibilidad para captar las diversas modulaciones de los paisajes y de las escenas históricas. Después de pasar por la geohistoria, Canguilhem instruyó su juicio filosófico en la medicina, y la vida humana (hombre/ medio) dejó su lugar a la vida misma (viviente/ medio), a la normatividad vital como elemento unificador de la experiencia. Pero la enseñanza de los vidalianos y del equipo de Estrasburgo nunca cayó en saco roto.

122 Pierre-Olivier Méthot, “On the genealogy,” 120-124.

${ }^{123}$ Un rotundo ejemplo de este argumento aparece al final de G. Canguilhem, La formation du concept de réflexe aux XVIIe et XVIIIe siècles (Paris: Vrin, 1977),165-166, cuando, conectando con las reflexiones de Georges Friedmann, relaciona la versión crecientemente mecanicista del concepto de "reflejo", desde 1850, con el desarrollo del taylorismo en el disciplinamiento de la fuerza laboral.

124 Pierre-Olivier Méthot, “On the genealogy,” 121-122.

125 Jones McAllester, "Georges Canguilhem on science and culture: learning biology's lessons," French Cultural Studies, [vol.] 11, 31 (2000): 120-125 (117-130).

126 Pietro Redondi, "Science moderne," 324-330. 